\title{
ECS effects: The PRE
}

\author{
J. B. KEYES and A. GRANT YOUNG \\ Louisiana State University, Baton Rouge, La. 70803
}

Sixty-four naive male albino rats were trained to leverpress for sucrose using a discrete trial procedure. Half of the Ss were trained on a continuous reinforcement schedule (CRF), and the other half were trained on a fixed-ratio schedule (FR). Following acquisition, on treatment day, a leverpress produced footshock followed by ECS (SECS), footshock only (SO), ECS only (ECSO), or no treatment (OO). Results of an extinction test $24 \mathrm{~h}$ after treatment showed that: (1) ECS produced apparent amnesia for footshock; (2) ECS eliminated the partial reinforcement effect (PRE); (3) footshock appeared to be a more effective suppressor in FR- than in CRF-trained Ss; (4) ECS alone produced a significantly increased rate of responding for CRF-trained Ss and a nonsignificant increased rate of responding for FR-trained Ss.

It is well established that when electroconvulsive shock (ECS) follows a one-trial learning experience, the result appears to be a retrograde amnesia (RA) for that learning experience (Lewis, 1969). This effect is usually explained in terms of a memory consolidation hypothesis which suggests that time is required, following sensory input, for the memory trace to become permanently fixed. Presumably, head trauma, such as that produced by ECS, disrupts this fixation process such that the memory is permanently lost.

A recent series of studies (Young \& Day, 1970; Young \& Day, 1971; Young \& Galluscio, 1970a, b) have produced what appears to be a curious by-product of ECS. In these studies, in order to separate the amnesic effect of ECS from any possible aversive effect, footshock was administered upon the emission of a previously learned leverpress. The footshock resulted in a suppressed rate of responding; however, if ECS immediately followed footshock, the result was apparent RA for the footshock. In addition, these studies found that Ss that experienced ECS were no different in extinction tests, regardless of whether lever training had been on a continuous reinforcement schedule (CR) or on a partial reinforcement schedule (PR). The effect of ECS, then, appeared to be an elimination of the partial reinforcement effect (PRE)-the greatly increased resistance to extinction shown by PR-trained animals.

It is not at all clear that this elimination of the PRE by ECS would be predicted by consolidation theory. Young \& Day (1971) suggested that the effect of ECS is not the disruption of a memory trace, resulting in RA, but rather, perhaps through disinhibition, the effect is to

*Based on a thesis submitted to Louisiana State University by the first author in partial fulfillment of the requirements for the MA degree. The research was supported in part by a grant from the Graduate Research Council, LSU, to the second author. increase perseveration of responding in extinction. Although ECS would presumably affect PR- and CR-trained Ss in the same manner, an inflated rate of responding in extinction would be much more obvious for CR-trained Ss, with their low resistance to extinction, than for PR-trained Ss, which typically respond at a high rate in extinction. Although this interpretation of the effect of ECS is tenable, it is also possible that a loss of the PRE is found because PR-trained Ss are less resistant to footshock. If footshock is a more effective suppressor for PR-than for CR-trained Ss, then the loss of the PRE would be due to a decreased rate of responding in extinction by PR-trained Ss, rather than an increased rate of responding by CR-trained Ss. Previous experiments have not had adequate controls to test this interpretation, and this experiment was done to determine which of these interpretations is most tenable.

\section{METHOD \\ Subjects}

The Ss were 64 naive male albino rats, $150-200 \mathrm{~g}$ in weight at the start of the experiment.

\section{Apparatus}

The apparatus consisted of two identical Scientific Prototype operant chambers, each enclosed in a sound-insulated ventilated cubicle. Each operant chamber had a grid floor, and fitted on the end wall was a retractable lever and a liquid dipper which dispensed $.01 \mathrm{ml}$ of a $40 \%$ sucrose solution used as reinforcement. All E-controlled events were operated by an electronic programming device.

\section{Procedure}

The Ss were selected randomly from the LSU colony and placed in individual cages on a food deprivation schedule of $10 \mathrm{~g}$ of Purina Chow every $24 \mathrm{~h}$. Water was available in the cages at all times and Ss were fed approximately $10 \mathrm{~min}$ after each experimental session.

After 4 days handling began, and from Days 5-8 Ss were handled in pairs for $5 \mathrm{~min}$ each day. On Day $9 \mathrm{Ss}$ began magazine training on a VI $30-\mathrm{sec}$ schedule. Experimental periods consisted of 20 presentations of the dipper and were continued for 4 days. On the 13 th day, all $S s$ were conditioned to leverpress, were allowed to make 50 reinforced responses, and, on the following day, were allowed to make 100 reinforced responses. On Day $15 \mathrm{Ss}$ were divided randomly into two groups, FR and $C R$, and acquisition training was begun. For the FR group, acquisition was under a FR-2 schedule for the first 5 days and under a FR-3 schedule for the next 5 days. Acquisition for the CR group was under a CRF schedule throughout. All Ss were given 100 leverpresses daily for 10 days. A discrete trial procedure was used, and the lever, which required $4 \mathrm{sec}$ to retract and extend fully, was inoperative during retraction.

On the day following completion of acquisition, each group was subdivided randomly, resulting in the following eight groups $(\mathrm{N}=8)$. 
Table 1

Mean Number of Leverpresses in Extinction

\begin{tabular}{llll}
\hline \multicolumn{1}{c}{ Group } & Total & Group & Total \\
\hline CR(OO) & 38.38 & FR(OO) & 56.13 \\
CR(SO) & 19.13 & FR(SO) & 27.50 \\
CR(SECS) & 46.00 & FR(SECS) & 55.50 \\
CR(ECSO) & 59.63 & FR(ECSO) & 67.63 \\
\hline
\end{tabular}

\section{Groups $C R$ (SECS) and FR(SECS)}

On treatment day, Ss in these two groups were fitted with a harness. Fine wire from an ECS source, which entered the operant chamber from the top, was connected to the harness and from the harness to microalligator clip electrodes which attached to S's ears. The harness permitted complete freedom of movement to all parts of the operant chamber. The first leverpress produced a 9-mA footshock of 2-sec duration, delivered through the grid floor, and the lever retracted. The offset of footshock initiated the onset of a 50-mA 500-m sec ECS, delivered through the earclip electrodes.

\section{Groups CR(ECSO) and FR(ECSO)}

The $S s$ in these two groups received treatment identical to that of the SECS groups above, except that no footshock preceded the administration of ECS.

\section{Groups $C R(S O)$ and $F R(S O)$}

The $S s$ in these two groups received treatment identical to that of the SECS groups, except that no ECS followed the administration of footshock.

\section{Groups $C R(O O)$ and $F R(O O)$}

The Ss in these two groups were controls. Treatment was identical to the SECS groups, except that leverpress produced neither footshock nor ECS.

All Ss were given a 10-min extinction test session $24 \mathrm{~h}$ after treatment. During extinction the stimulus conditions were the same as during acquisition, except that the dipper was inoperative.

\section{RESULTS}

The total number of responses made by each $S$ in extinction were recorded, and results showed that more responses were made by Group FR(ECSO), followed in order by Groups CR(ECSO), FR(OO), FR(SECS), CR(SECS), CR(OO), FR(SO), and CR(SO). These data were subjected to an analysis of variance which showed that main effects of both schedule and treatment were significant beyond the .01 level. The Schedule by Treatment interaction did not reach significance at the .05 level. Group comparisons $(t)$ showed the following significant beyond the .01 level: $\mathrm{CR}(00)$ vs $\mathrm{FR}(00)$, $\mathrm{CR}(\mathrm{OO})$ vs $\mathrm{CR}(\mathrm{SO}), \mathrm{CR}(\mathrm{OO})$ vs $\mathrm{CR}(\mathrm{ECSO}), \mathrm{CR}(\mathrm{SO})$ vs CR(SECS), CR(SO) vs CR(ECSO), FR(OO) vs FR(SO), FR(SO) vs FR(SECS), FR(SO) vs FR(ECSO). The comparison CR(SECS) vs CR(ECSO) was significant beyond the .05 level. All other group comparisons were not significant at the .05 level. The mean number of responses in extinction for all groups is shown in Table 1.
Response rates were recorded for the last 2 days of acquisition and, although there were no significant differences within CR or FR groups, the FR-trained Ss were significantly slower than the CR-trained Ss $(\mathrm{p}<.01$, Mann-Whitney $\mathrm{U}$ test $)$ due to the discrete trial procedure.

\section{DISCUSSION}

The finding that the FR(OO) group made significantly more responses in extinction than did the CR(OO) groups is the usual PRE and was expected. Likewise, the finding that the SECS groups made significantly more responses in extinction than did the SO groups replicates earlier findings, which usually are explained in terms of consolidation theory.

The finding that there was little difference between the FR(SECS) and CR(SECS) groups also replicates earlier findings (i.e., Young \& Day, 1970; Young \& Galluscio, 1971) showing a loss of the PRE for Ss which experience ECS.

The fact that there was no significant difference between the FR(SO) and CR(SO) groups would lend support to the idea that footshock may be a more effective suppressor for FR-trained than for CR-trained Ss. Although this effect would tend to reduce the difference between the groups and thus eliminate the PRE, it does not seem that this effect is the primary cause of the loss of the PRE. A comparison of the Ss which experienced ECS only (ECSO) and those which received no treatment $(\mathrm{OO})$ indicates that the effect of ECS, administered by itself, was to greatly increase the number of responses made in extinction. Although there is an increased rate of responding for both FR(ECSO) and CR(ECSO) groups, the effect is much more pronounced in the CR than in the FR group. This could be due to the initially greater resistance to extinction of PR-trained Ss.

If the net effect of ECS is simply an inflated rate of responding, then any comparison between groups which experience footshock only and those which experience footshock followed by ECS would make it appear that ECS had produced RA, perhaps through a failure of the memory trace for footshock to become permanently fixated.

Why ECS should produce an increased rate of responding in extinction is not clear. It may be, as suggested by Young \& Day (1971), that the effect is one of disinhibition. Perhaps ECS acts to increase the drive level, or level of general activity, in some way, and this increased drive is channeled into the response that the organism has learned to make in that stimulus situation.

In any case, the present study adds to the growing body of evidence which suggests that a memory consolidation hypothesis is not the proper explanation for the effect of ECS.

\section{REFERENCES}

Lewis, D. J. Sources of experimental amnesia. Psychological Review, 1969, 76, 461-472.

Young, A. G., \& Day, H. D. ECS effects following continuous and partial reinforcement training. Psychonomic Science, $1970,21,131-132$

Young, A. G., \& Day, H. D. Effect of ECS on one-trial learning and on the partial reinforcement effect. Psychonomic Science, 1971, 24, 99-100.

Young, A. G., \& Galluscio, E. H. Failure of ECS to produce retrograde amnesia following partial reinforcement training. Psychonomic Science, 1970a, 18, 175-176.

Young, A. G., \& Galluscio, E. H. Effects of ECS on one-trial learning following continuous and partial reinforcement training. Psychonomic Science, 1970b, 21, 43-44.

(Received September 11, 1972.) 